\title{
Geography Notes and Definitions
}

\section{Statistical Regions of the United Kingdom}

The statistical regions of the UK comprise the Regions of England together with Wales, Scotland and Northern Ireland.

\section{Regions: England}

The Regions of England were formerly known as Government Office Regions (GORs) until their closure in March 2011. Government Offices for the Regions were established across England in 1994. In 1996, GORs became the primary classification for the presentation of regional statistics. The Government Office for the North West merged with the Government Office for Merseyside in August 1998. In tables, the East of England (formerly the Eastern Region) is referred to as East.

\section{Local government}

\section{England}

The local government structure remains largely as defined at 1 April 1998. The implementation of local government reorganisation in England took place in four phases on 1 April in each year between 1995 and 1998. The reorganisation involved only the non-metropolitan counties. Unitary Authorities (UAs) replaced the two-tier system of County Councils and Local Authority District Councils in parts of some shire counties and, in some instances, across the whole county. For statistical purposes grouping UAs by geography can be helpful.

By legal definition all unitary authorities in England are counties. However, for many purposes the unitary authorities are treated as districts. For the majority of unitary authorities their establishment was achieved without geographical change. However, for a few unitary authorities, there were some boundary changes at District and Ward levels, most notably, the County of Herefordshire UA in the West Midlands and Peterborough UA in the East of England.

On the 1 April 2009 there was a further local government reorganisation that created nine further unitary authorities in England. The tables will change to include these as datasets move onto the new geography. The map shows both old and new administrative areas. Details of the changes are given below (continued after map).

- Country Durham UA comprises the former districts of Chester-le-Street, Derwentside, Durham, Easington, Sedgefield, Teesdale and Wear Valley

- Northumberland UA comprises the former districts of Alnwick, Berwick-upon-Tweed, Blyth Valley, Castle Morpeth, Tynedale and Wansbeck

- Cheshire East UA comprises the former districts of Congleton, Crewe and Nantwich and Macclesfield

- Cheshire West and Chester UA comprises the former districts of Chester, Ellesmere Port \& Neston and Vale Royal 


\section{Counties and unitary authorities in England, $1998^{1}$ and $2009^{2}$}

1 Hartlepool

2 Middlesbrough

3 Redcar and Cleveland

4 Stockton-on-Tees

5 Darlington

6 Halton

7 Warrington

8 Blackburn with Darwen

9 Blackpool

10 East Riding of Yorkshire

11 City of Kingston upon Hull

12 North East Lincolnshire

13 North Lincolnshire

14 York

15 Derby

16 Leicester

17 Rutland

18 Nottingham

19 County of Herefordshire

20 Telford and Wrekin

21 Stoke-on-Trent

22 Luton

23 Peterborough

24 Southend-on-Sea

25 Thurrock

26 Bracknell Forest

27 Reading

28 Slough

29 West Berkshire

30 Windsor and Maidenhead

31 Wokingham

32 Milton Keynes

33 Brighton and Hove

34 Portsmouth

35 Southampton

36 Isle of Wight

37 Medway

38 Bath and North

East Somerset

39 City of Bristol

40 North Somerset

41 South

Gloucestershire

42 Plymouth

43 Torbay

44 Bournemouth

45 Poole

46 Swindon
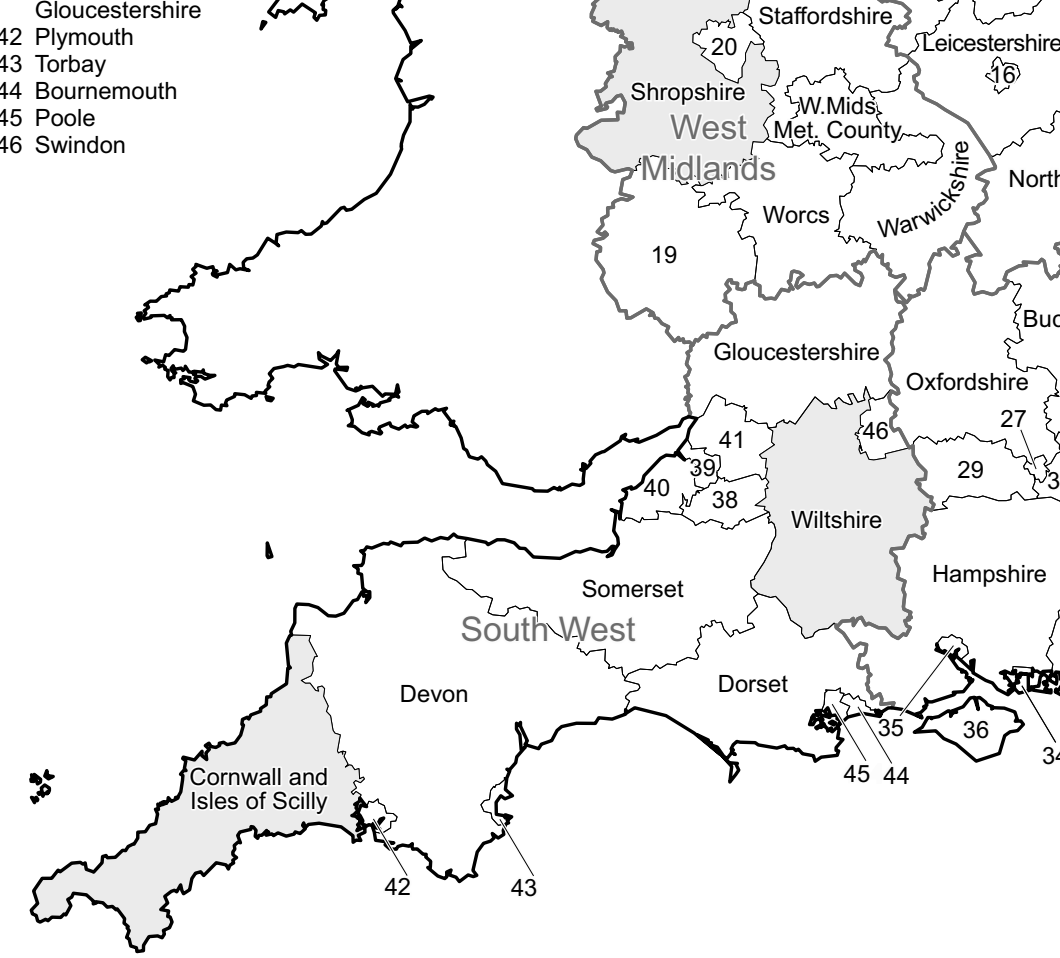

Merseysid

$9 \sqrt{3}$ Lancashire West Yorkshires 10

Local government structure post April 2009²
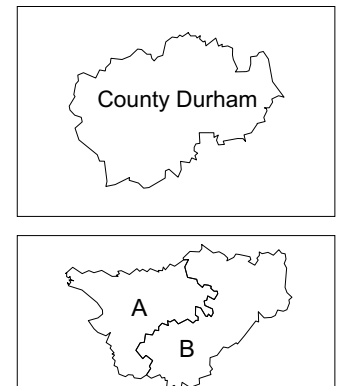

A Cheshire West and Chester B Cheshire East
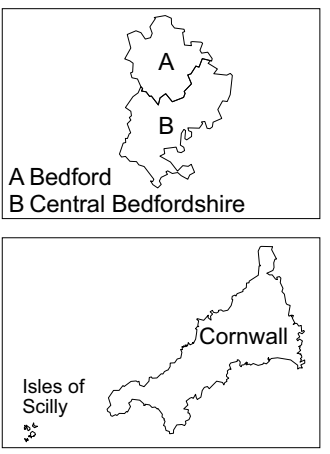

:

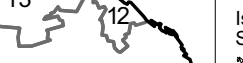

Lincolnshire

East Midlands
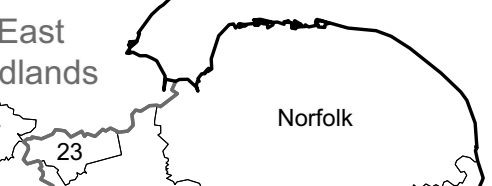

Norfolk

West wW.Mids
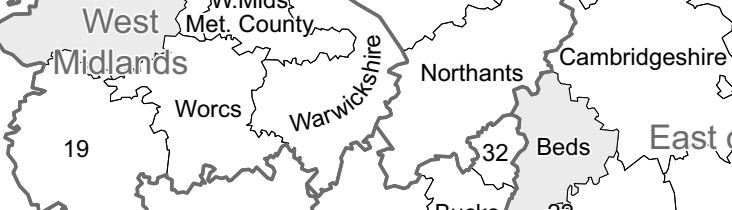

Cambridgeshire

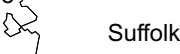

Suffolk

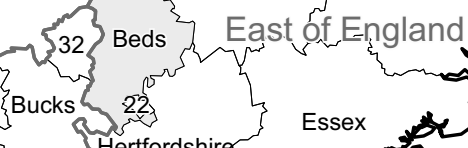

Essex
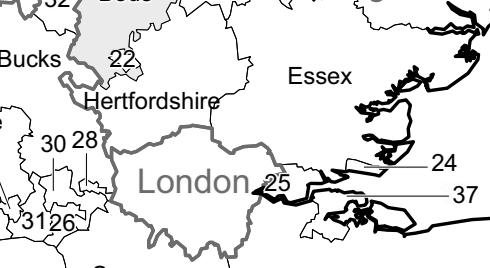

don
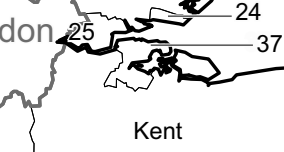

South

Kent

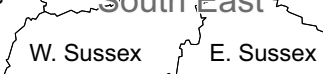

W. Sussex E. Sussex

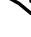

34

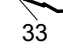

Unitary authorites from 1st April 2009

Contains Ordnance Survey data (C) Crown copyright and database right 2011

1 Local government structure as at April 1998.

2 Areas affected by changes on 1st April 2009 are shaded blue. 
- Shropshire UA comprises the former districts of Bridgnorth, North Shropshire, Oswestry, Shrewsbury and Atcham, and South Shropshire

- Bedford UA comprises the former district of Bedford

- Central Bedfordshire UA comprises of the former districts of Mid Bedford and South Bedfordshire.

- Cornwall UA comprises the former districts of Caradon, Carrick, Kerrier, North Cornwall, Penwith and Restormel

- Isles of Scilly was recoded as a separate area

- Wiltshire UA comprises the former districts of Kennet, North Wiltshire, Salisbury and West Wiltshire.

Full details of administrative geography can be found at: www.statistics.gov.uk/geography/beginners guide.asp

\section{Wales}

On 1 April 1996, the 8 counties and 37 districts of Wales were replaced by 22 Unitary Authorities. These Unitary Authorities are usually presented in alphabetical order.

\section{Unitary authorities in Wales, 2005 Awdurdodau unedol yng Nghymru}

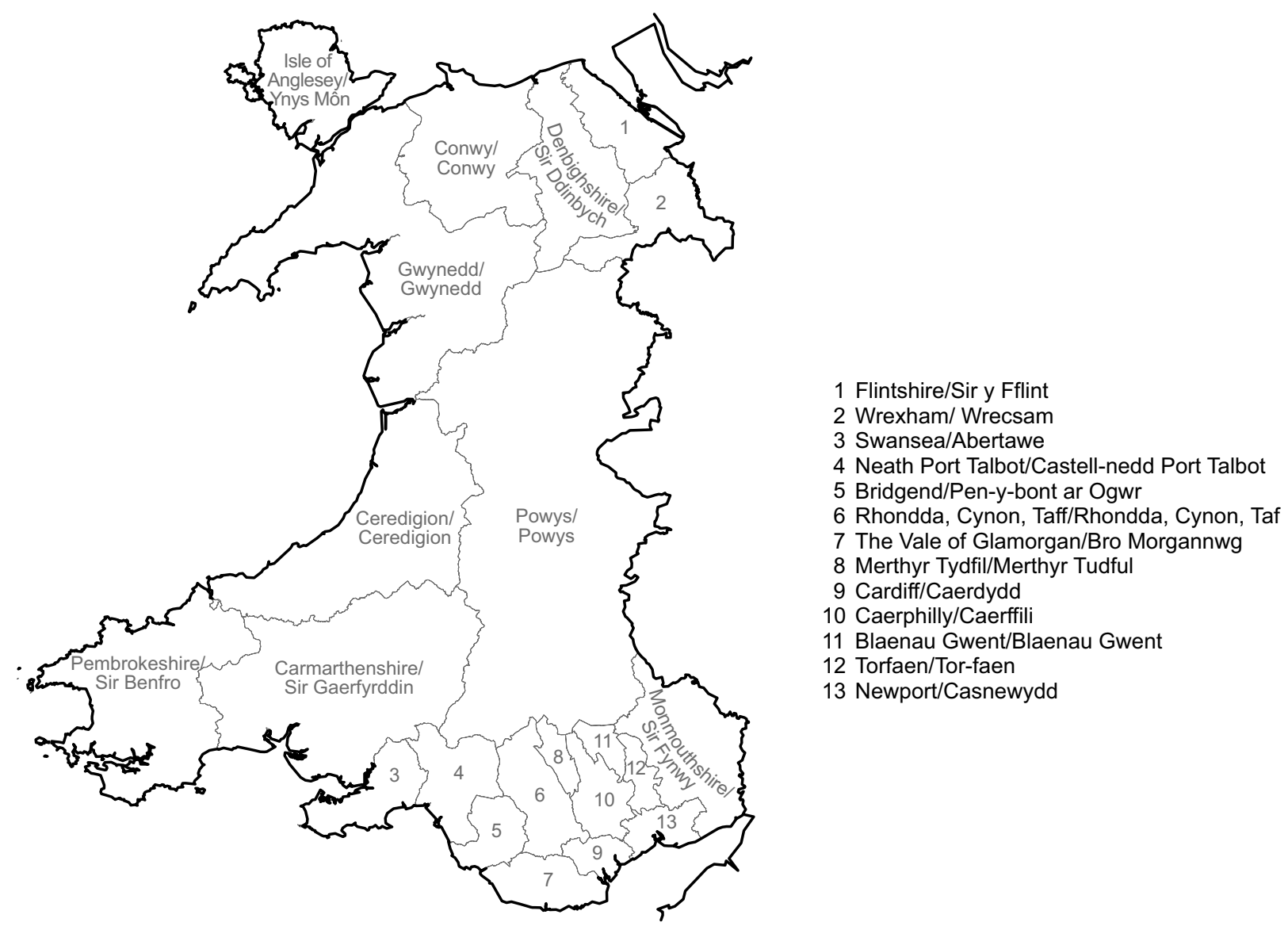

Contains Ordnance Survey data @ Crown copyright and database right 2011 


\section{Scotland}

On 1 April 1996, the 10 local authority regions and 56 districts of Scotland were replaced by 32 unitary Councils. These Councils are usually presented in alphabetical order.

\section{Councils in Scotland, 1996}

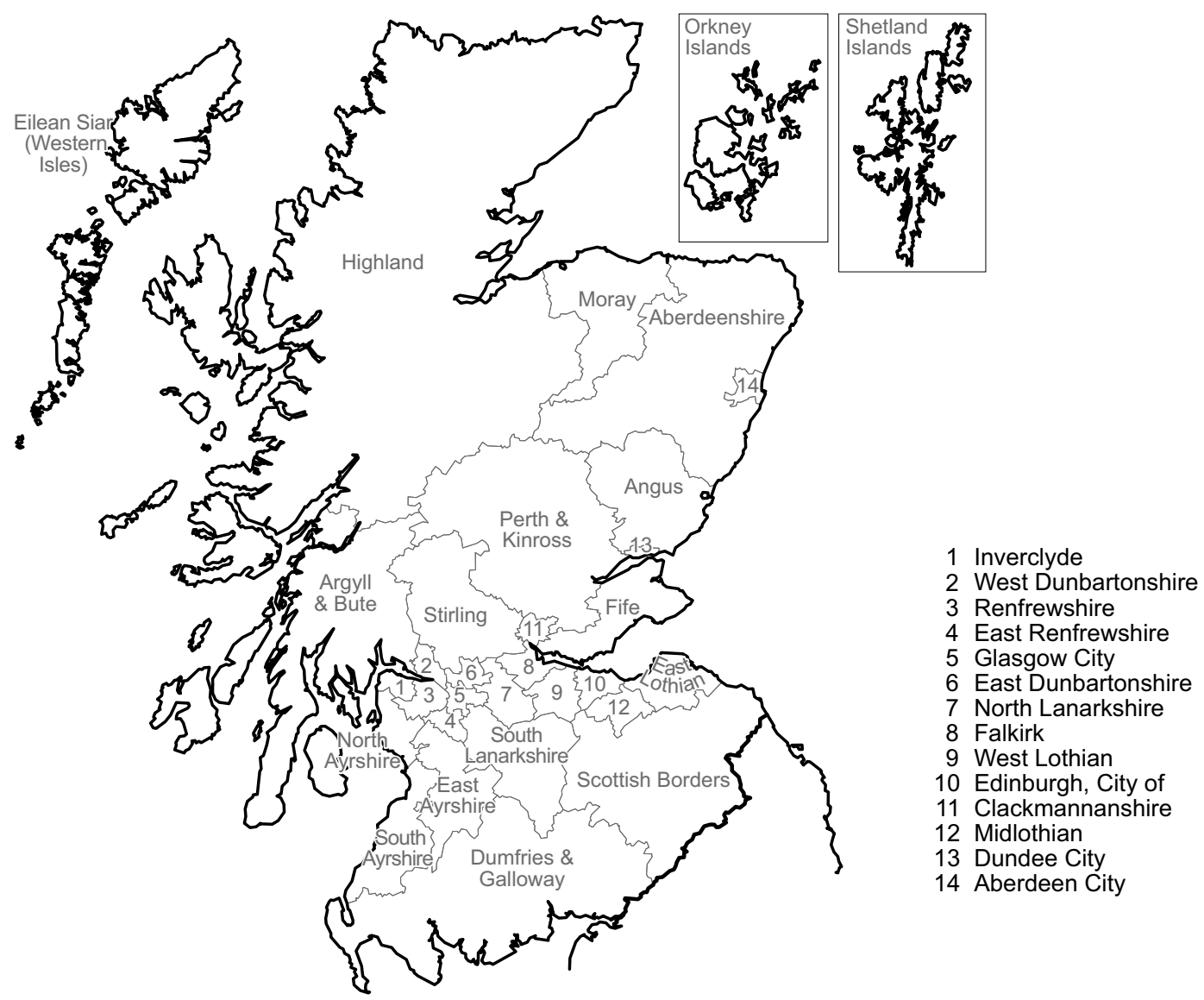

Contains Ordnance Survey data @ C Crown copyright and database right 2011 


\section{Northern Ireland}

The 26 districts of Northern Ireland are presented in the local authority key statistics tables.

\section{District Councils in Northern Ireland, 1992}

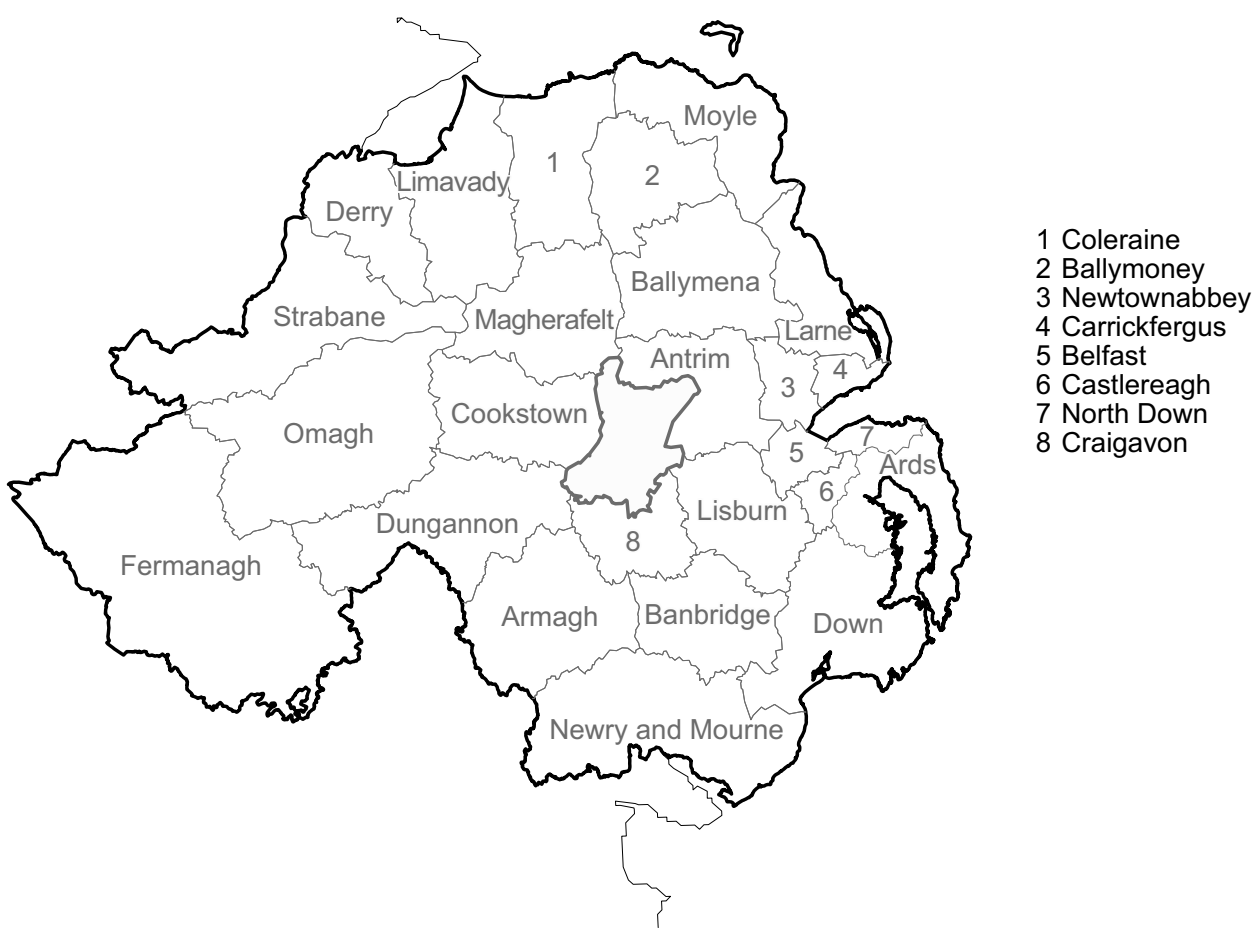

Contains Ordnance Survey data @ C Crown copyright and database right 2011

\section{NUTS (Nomenclature of Territorial Statistics) area classification}

NUTS is a hierarchical classification of areas that provides a breakdown of the European Union's economic territory for producing regional statistics that are comparable across the Union. It has been used since 1988 in EU legislation for determining the distribution of the Structural Funds. The NUTS five-tier structure for the United Kingdom (UK) was reviewed during 1998 as a consequence of the move to using Government Office Regions as the principal classification for English Regions and the local government re-organisation that took place in the same year. The NUTS structure comprises current national administrative areas, except in Scotland where some NUTS areas comprise whole and/or part local enterprise company areas.

As a result of a European Union-wide NUTS regulation enacted in June 2003 it is now obligatory to use the NUTS geographies in the regulation (including the new codes). There are only minimal changes for the UK, although NUTS levels 4 and 5 no longer have any official status and should be referred to as LAU (Local Administrative Unit) 1 and 2 respectively.

The NUTS classification is reviewed periodically: the latest changes were agreed in 2008. 


\section{NUTS levels 1, 2 and 3 in England,,${ }^{1} 2008$}

NUTS level 3 areas

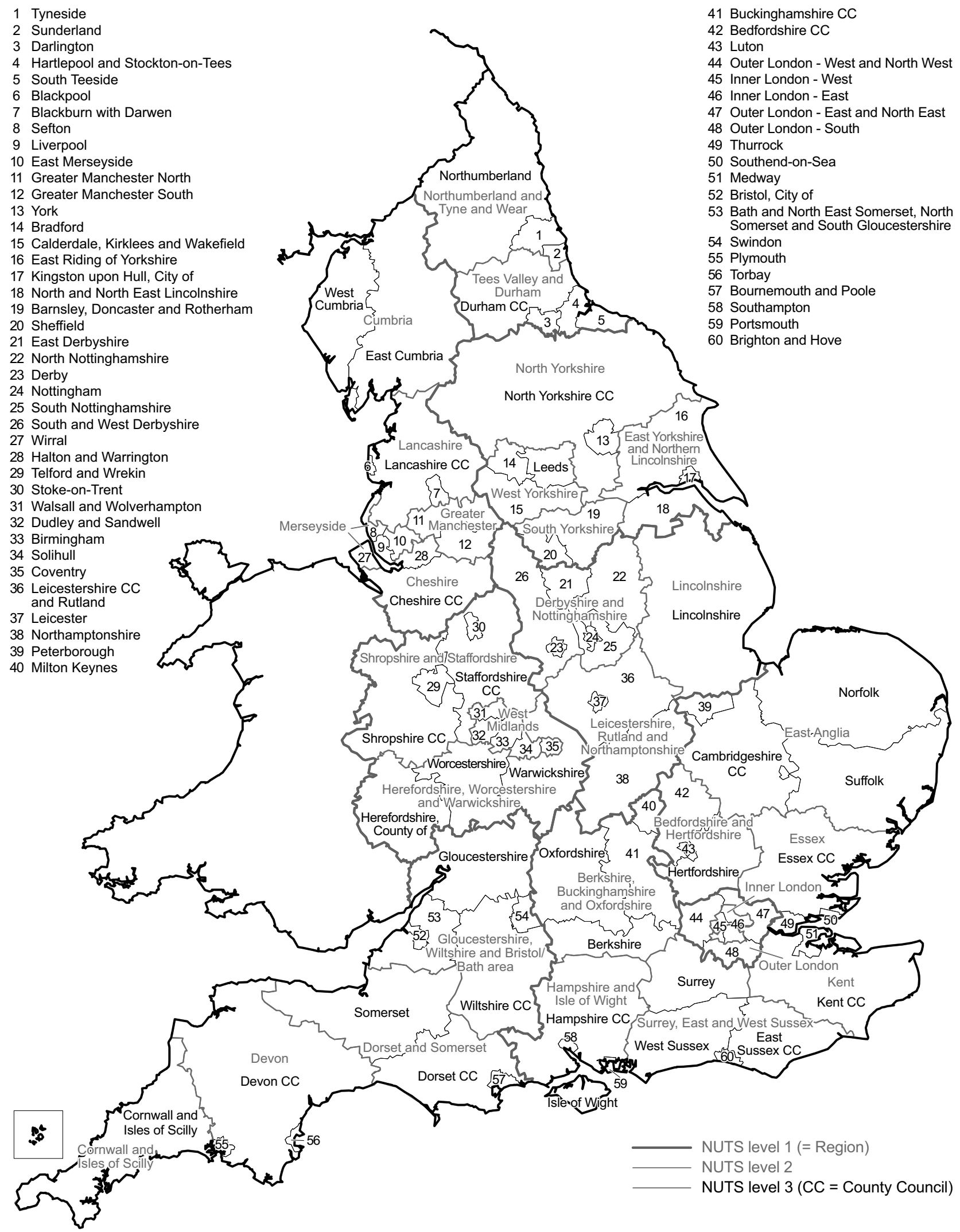

Contains Ordnance Survey data ( Crown copyright and database right 2011

1 NUTS (Nomenclature of Units for Territorial Statistics) is a hierarchical classification of areas that provides a breakdown of the EU's economic territory. 
NUTS levels 1, 2 and 3 in Wales, ${ }^{1} 2008$

NUTS lefelau 1, 2 a 3 yng Nghymru, ${ }^{1} 2008$

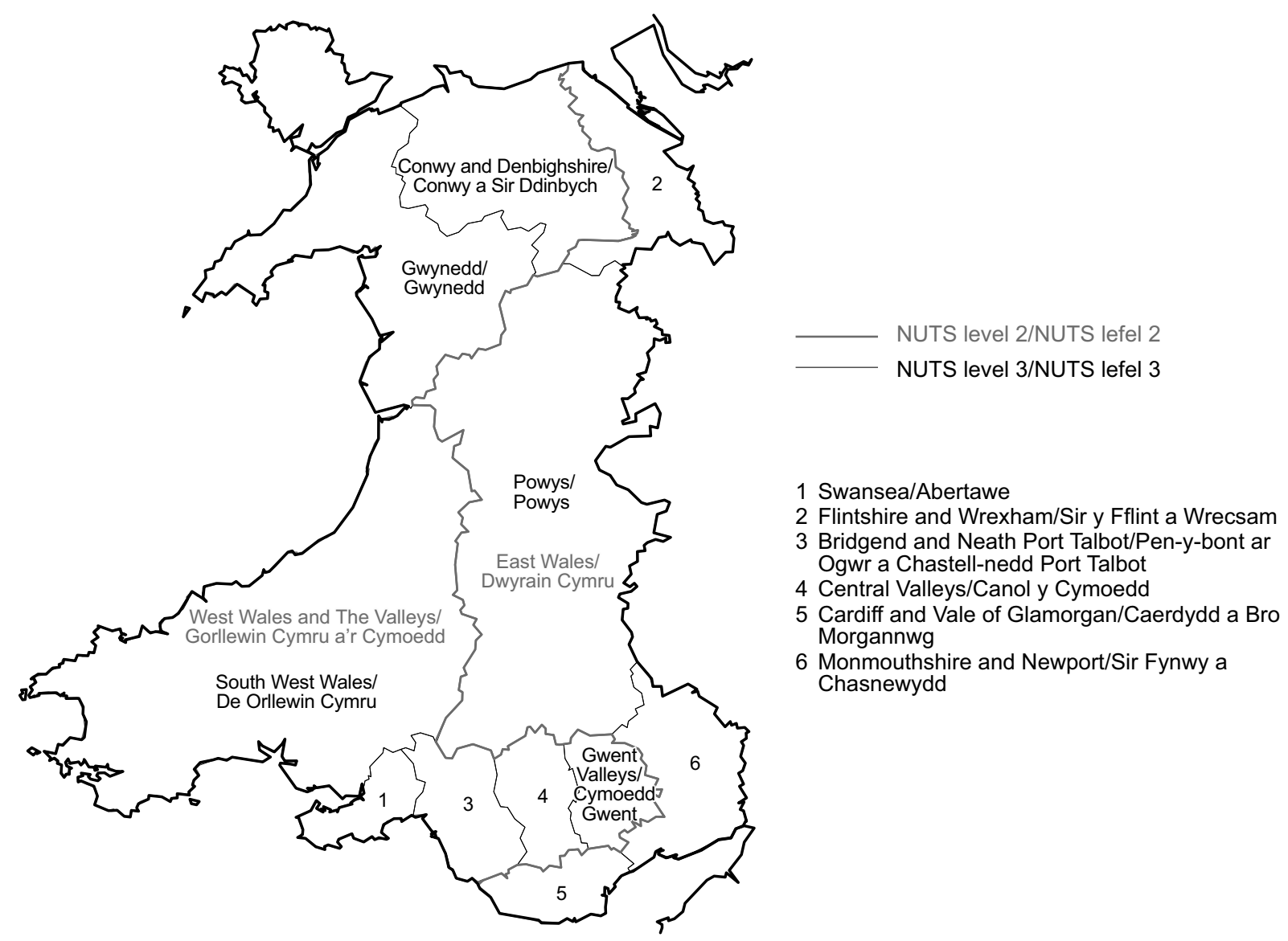

Contains Ordnance Survey data @ Crown copyright and database right 2011

1 NUTS (Nomenclature of Units for Territorial Statistics) is a hierarchical classification of areas that provides a breakdown of the EU's economic territory. The NUTS level 1 area is the whole country.

Mae NUTS (Enwau Unedau Tiriogaethol at Ddibenion Ystadegaeth) yn ddosbarthiad hierarchaidd o ardaloedd sy'n darparu dadansoddiad o diriogaeth economaidd yr UE. Yr ardal NUTS lefel 1 yw'r wlad gyfan. 
NUTS levels 1, 2 and 3 in Scotland, ${ }^{1} 2008$

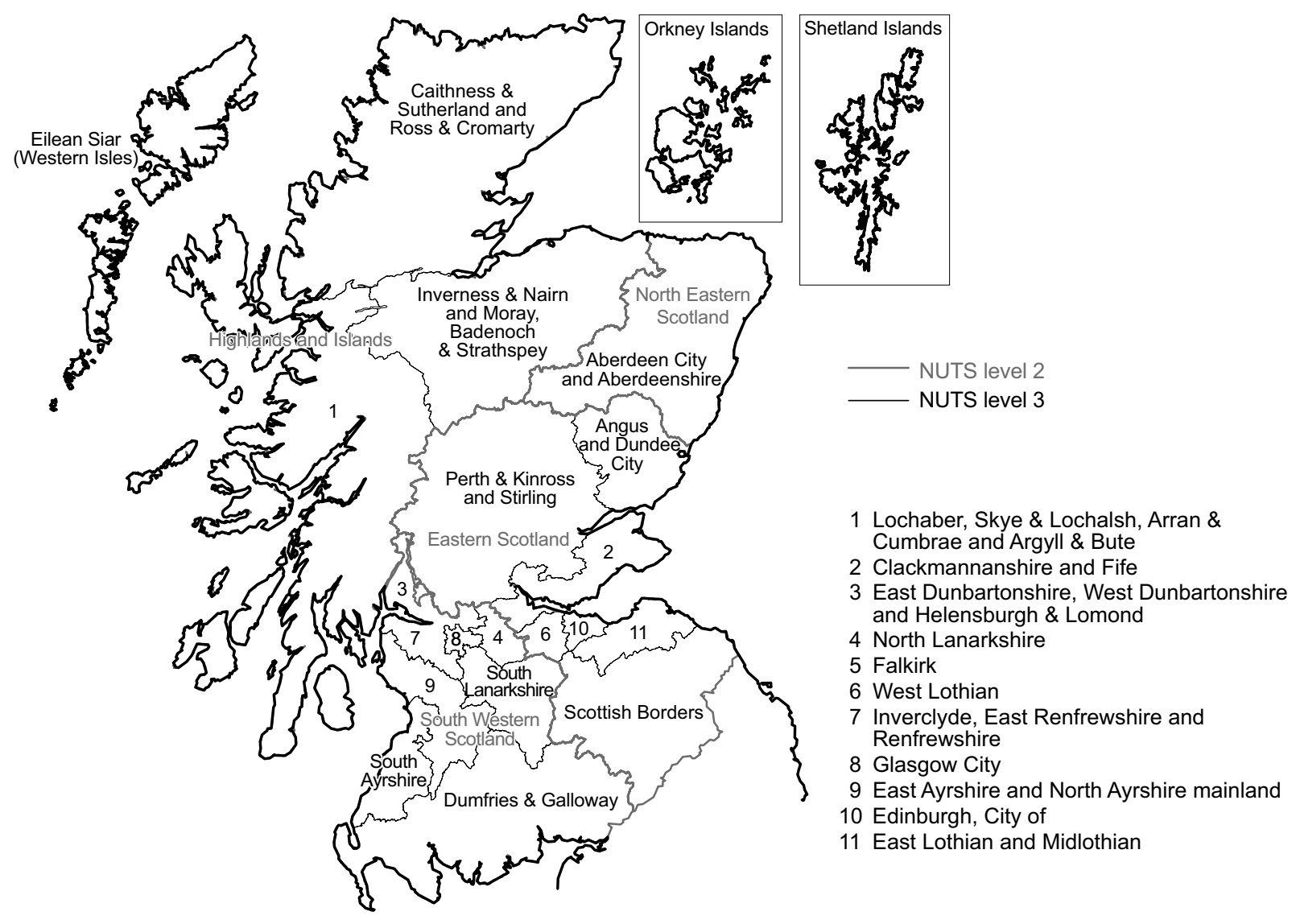

\section{NUTS levels 1, 2 and 3 in Northern Ireland, ${ }^{1} 2008$}

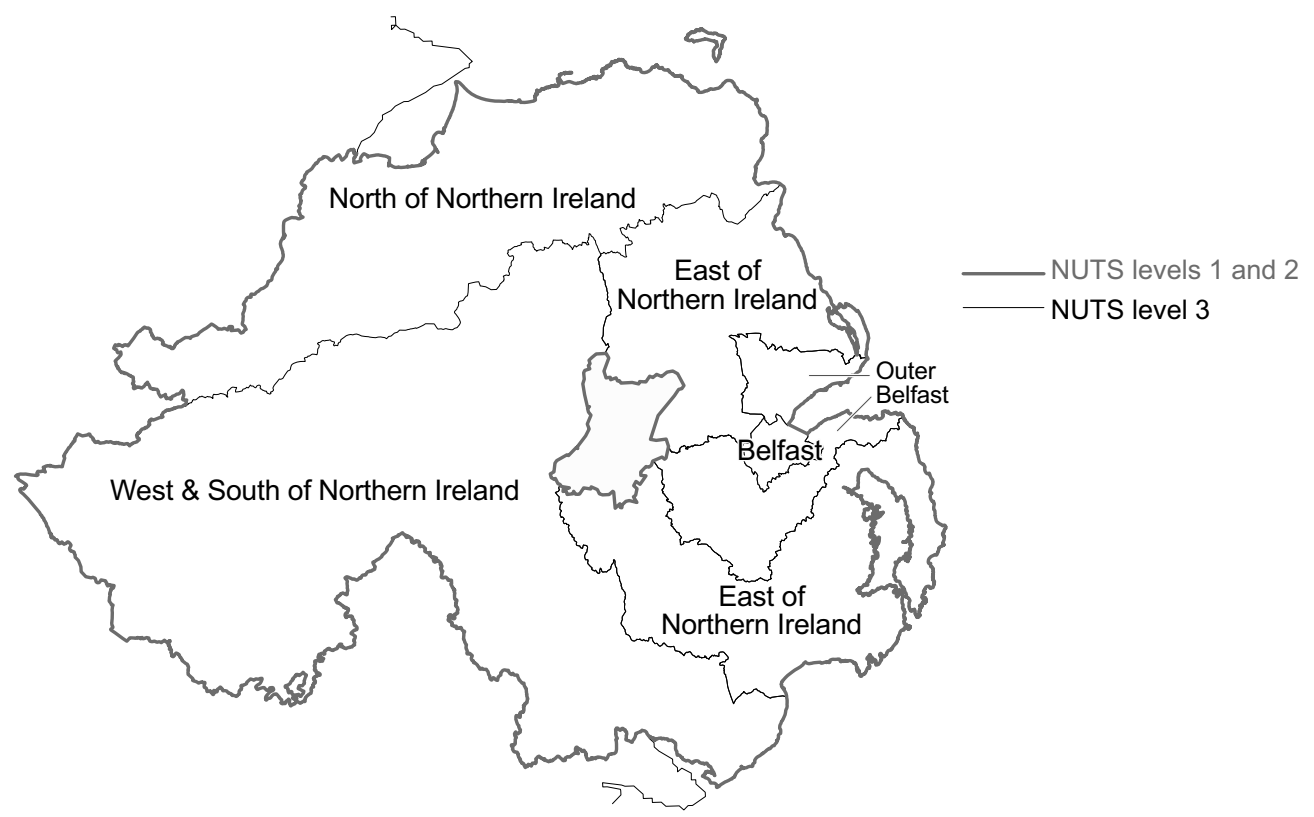

Contains Ordnance Survey data () Crown copyright and database right 2011

1 NUTS (Nomenclature of Units for Territorial Statistics) is a hierarchical classification of areas that provides a breakdown of the EU's economic territory. The NUTS level 1 area is the whole country in Scotland and NUTS levels 1 and 2 cover the whole of Northern Ireland. 


\section{Economy: Regional Accounts}

The UK Continental Shelf, now referred to as Extra-Regio, is treated as a separate region in Regional Accounts.

\section{Environment: England}

Environment Agency regions are used for several tables, but rainfall data are still provided for the regions of the former National Rivers Authority (NRA), which became part of the Environment Agency upon its creation in 1996. The NRA regions are identical to the Environment Agency regions except the North East and South Western regions which were each formed from two NRA regions.

\section{Health: England}

On 1 April 2002 a new organisation was introduced for the National Health Service (NHS) in England. Twenty-eight Strategic Health Authorities (SHAs) replaced the old 95 Health Authorities. In February 2004 the Strategic Health Authority of Coventry, Warwickshire, Herefordshire and Worcestershire changed their name to West Midlands South.

On July 12006 , the number of SHAs was reduced to ten. The areas were the same as the Government Office Regions (GORs) except for the South East which is split in to South East Coast and South East Central. Strategic Health Authorities manage the NHS locally and are a key link between the Department of Health and the NHS. They are responsible for:

- developing plans for improving health services in their local area

- making sure local health services are of a high quality and are performing well

- increasing the capacity of local health services - so they can provide more services, and

- making sure national priorities - for example, programmes for improving cancer services - are integrated into local health service plans

\section{Education authorities}

Local level education data for England and Northern Ireland are available for education 'authorities' and 'boards' respectively. 


\section{Environment Agency regions, England and Wales, 1996}

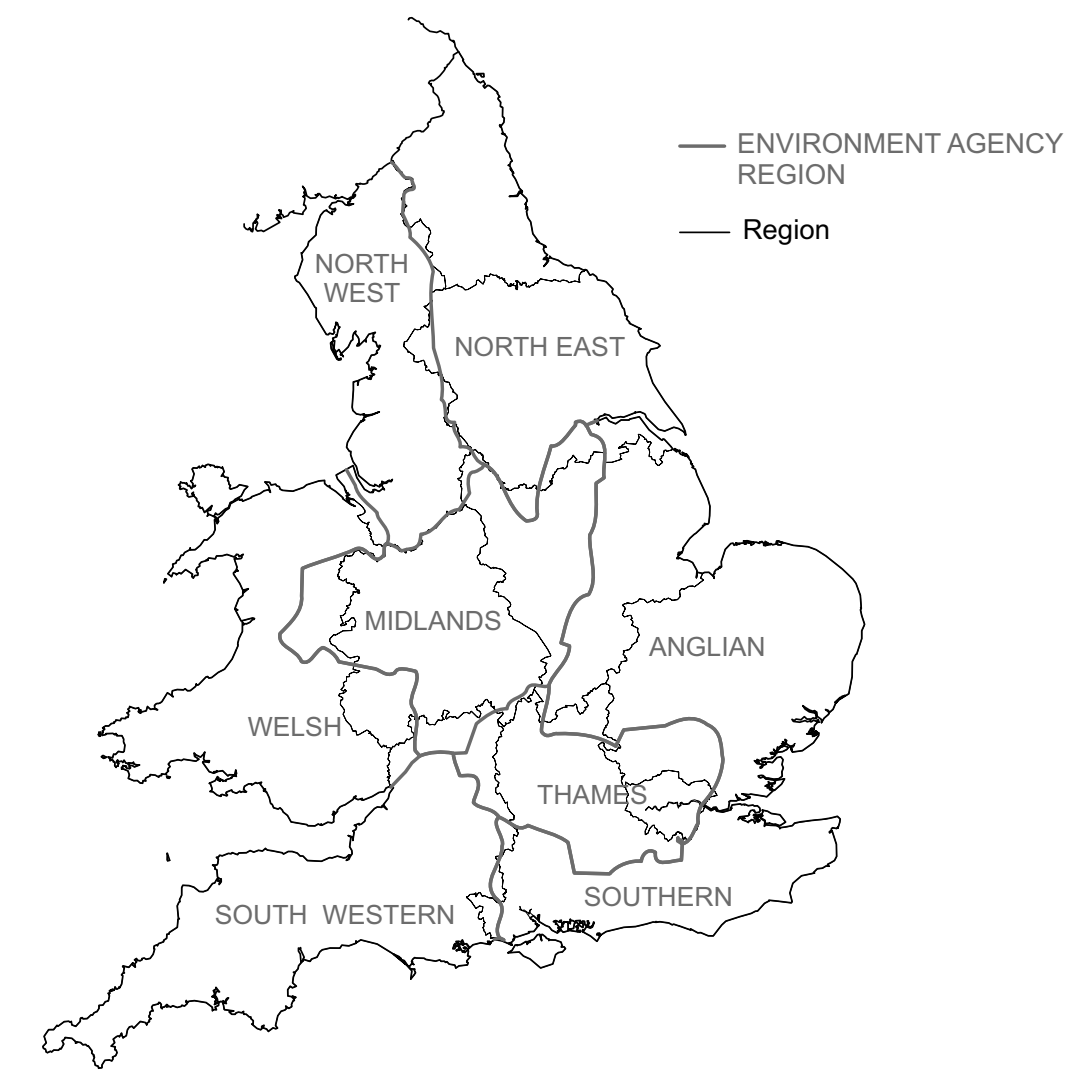

\section{Regions of the National Rivers Authority ${ }^{1}$, England}

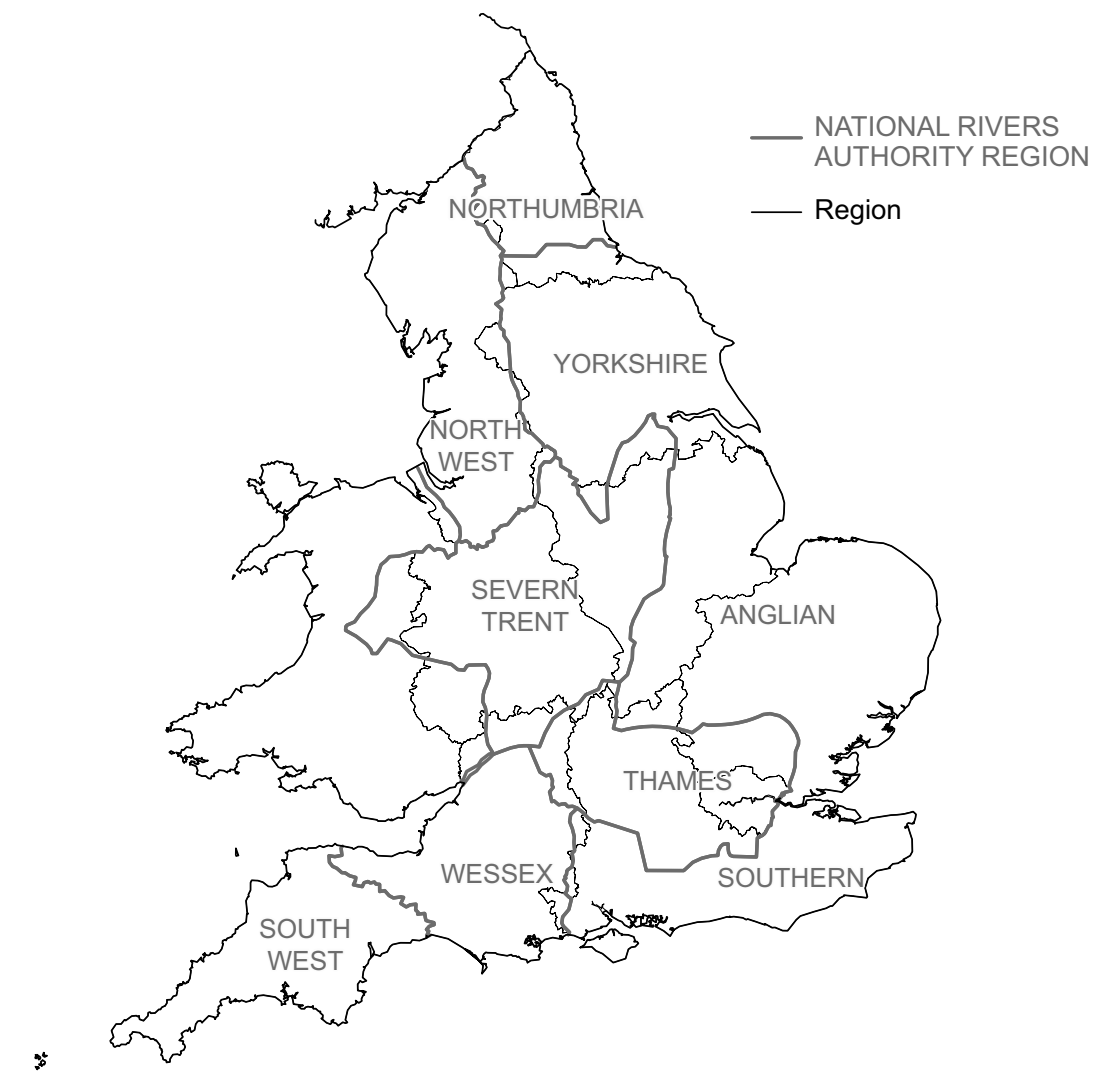

Contains Ordnance Survey data ๑ Crown copyright and database right 2011

1 The nine original NRA regions as used for rainfall data. The NRA became part of the Environment Agency upon its creation in 1996. 
Health areas in England, 2006

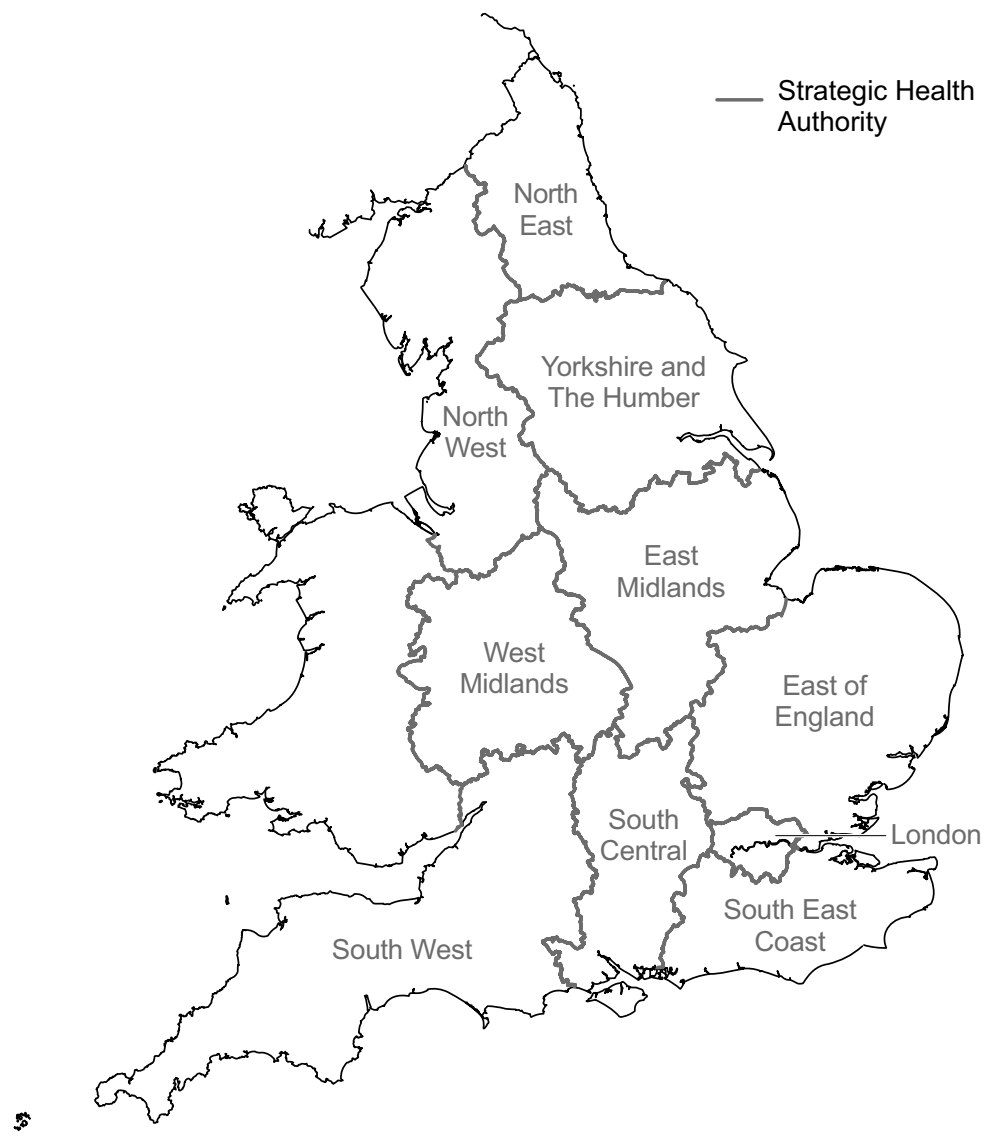

Contains Ordnance Survey data @ Crown copyright and database right 2011 


\section{Education authorities in England}

1 North Tyneside

2 Newcastle upon Tyne

3 Gateshead

4 South Tyneside

5 Sunderland

6 Hartlepool

7 Stockton-on-Tees

8 Darlington

9 Middlesbrough

10 Redcar and Cleveland

11 Kingston upon Hull

12 North Lincolnshire

13 North East Lincolnshire

14 Calderdale

15 Kirklees

16 Wakefield

17 Barnsley

18 Sheffield

19 Rotherham

20 Doncaster

21 Derby

22 Nottingham

23 Leicester

24 Rochdale

25 Oldham

26 Tameside

27 Stockport

28 Manchester

29 Bury

30 Blackburn with Darwen

31 Bolton

32 Wigan

33 Salford

34 Trafford

35 Warrington

36 St Helens

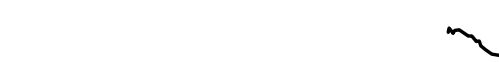

.




\section{Northern Ireland}

Education data for Northern Ireland are shown for the five Education and Library Boards. The districts comprising the Education and Library Boards are as follows:

\begin{tabular}{|l|l|}
\hline Board & Districts \\
\hline Belfast & Belfast \\
\hline South Eastern & Eastern Ards, Castlereagh, Down, Lisburn, North Down \\
\hline Southern & $\begin{array}{l}\text { Armagh, Banbridge, Cookstown, Craigavon, Dungannon, } \\
\text { Newry and Mourne }\end{array}$ \\
\hline North Eastern & $\begin{array}{l}\text { Antrim, Ballymena, Ballymoney, Carrickfergus, Coleraine, } \\
\text { Larne, Magherafelt, Moyle, Newtownabbey }\end{array}$ \\
\hline Western & Derry, Fermanagh, Limavady, Omagh, Strabane \\
\hline
\end{tabular}

\section{Education and Library Boards in Northern Ireland, 1992}

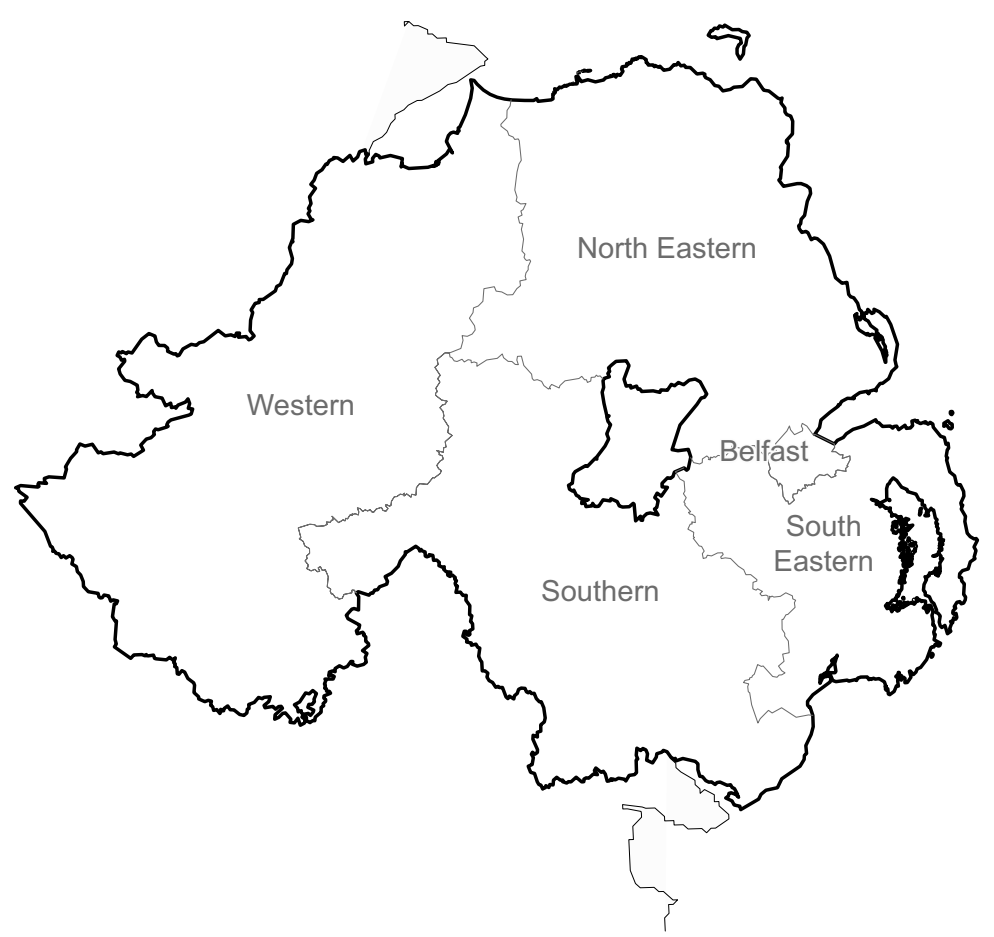

Contains Ordnance Survey data @ Crown copyright and database right 2011 